\title{
Forest cover change prediction using hybrid methodology of geoinformatics and Markov chain model: A case study on sub-Himalayan town Gangtok, India
}

\author{
Anirban Mukhopadhyay ${ }^{1, *}$, Arun Mondal $^{2}$, Sandip MukherjeE $^{3}$, Dipam Khatua ${ }^{1}$, \\ Subhajit Ghosh ${ }^{1}$, Debasish Mitra ${ }^{4}$ and Tuhin Ghosh ${ }^{1}$ \\ ${ }^{1}$ School of Oceanographic Studies, Jadavpur University, Kolkata, India. \\ ${ }^{2}$ Department of Water Resources Management and Development, Indian Institute of Technology, Roorkee, India. \\ ${ }^{3}$ TERI University, New Delhi, India. \\ ${ }^{4}$ Department of Marine and Atmospheric Sciences, Indian Institute of Remote Sensing, Dehradun, India. \\ ${ }^{*}$ Corresponding author.e-mail: anirban_iirs@yahoo.com
}

In the Himalayan states of India, with increasing population and activities, large areas of forested land are being converted into other land-use features. There is a definite cause and effect relationship between changing practice for development and changes in land use. So, an estimation of land use dynamics and a futuristic trend pattern is essential. A combination of geospatial and statistical techniques were applied to assess the present and future land use/land cover scenario of Gangtok, the subHimalayan capital of Sikkim. Multi-temporal satellite imageries of the Landsat series were used to map the changes in land use of Gangtok from 1990 to 2010. Only three major land use classes (built-up area and bare land, step cultivated area, and forest) were considered as the most dynamic land use practices of Gangtok. The conventional supervised classification, and spectral indices-based thresholding using NDVI (Normalized Difference Vegetation Index) and SAVI (Soil Adjusted Vegetation Index) were applied along with the accuracy assessments. Markov modelling was applied for prediction of land use/land cover change and was validated. SAVI provides the most accurate estimate, i.e., the difference between predicted and actual data is minimal. Finally, a combination of Markov modelling and SAVI was used to predict the probable land-use scenario in Gangtok in 2020 AD, which indicted that more forest areas will be converted for step cultivation by the year 2020 .

\section{Introduction}

The study of land use/land cover (LULC) dynamics and its definite pattern of change is very important for monitoring environmental conditions and for impact assessment. LULC in every urban area is changing rapidly due to the increasing population and pressure of urbanization (Voogt and Oke 2003). The limitation of space in the core urban area is compelling people to settle in its peripheral or suburban regions at a fast rate (Miller and
Small 2003). The cultivated areas, wetlands, forests, and water bodies are being converted to meet the demands of infrastructure and facility installations. Remote sensing provides the privilege of rapid data acquisition of land-use information at a lower cost than ground survey methods (Pal and Mather 2004). Satellite imageries, that provide time series data of LULC, are useful to identify the spatio-temporal changes and their probable impact on the environment. Forests are one of the most important components of the land

Keywords. Land-use dynamics; Markov chain modelling; NDVI; SAVI; supervised classification. 
cover of Himalayan area, as they serve numerous functions related to biodiversity conservation (Alcorn 1993); as a habitat for indigenous species and medicinal herbs, to control floods, soil erosion, and greenhouseemissions (Balick 1990; Phillips et al. 1998; Laurance 1999a, b; Bruijnzeel 2004; Bradshaw et al. 2007; Mollicone et al. 2007), to regulate water supplies and to facilitate pollination for agricultural system.

Large parts of South America, Africa, and south/ southeast Asia are undergoing rampant deforestation (mostly conversion of forested areas into agricultural lands). Today, forests occupy only $31 \%$ of the total land area of the earth (FAO 2010). The driving forces behind such deforestation include cattle ranching, shifting cultivation, step farming, demand for fuel wood, etc. (Allen and Barnes 1985; Chakraborty 1994; Myers 1994). This is very common in mountainous areas like the Himalayas, especially the northeastern states of India. So, forest cover assessment is an important component of many environmental models and is also a reliable component of land-use change (Zhang et al. 2006). Therefore, an accurate estimate of the extent of forests within a specific area is essential for its better management as well as to develop resource allocation strategies. Remote sensing data is being used for this estimation, as forest cover changes occur very fast, both spatially and temporally, and forests are, not easily accessible.

Change detection study for LULC was performed by many researchers particularly in urban areas. He et al. (2000) and Zhang et al. (2002) used multi-temporal remote sensing images for analysing LULC in the metropolitan region of Beijing. Liu and Zhou (2005) analyzed the spatial pattern of urbanization and predicted future urban expansion. Zhou and Hou (2009) and Chen et al. (2009) used multi-temporal Landsat TM images to establish land-use databases and provided the spatiotemporal characteristics of land-cover changes of a Chinese city. Use of multi-temporal satellite images for the detection of land-use change and its spatio-temporal pattern has been considered and it has proved to be an efficient approach by Masek et al. (2000); Herold et al. (2003) and Dietzel et al. (2005). Land-use change level and conversion of land-use type was carried out by Zhang et al. (2010).

Markov chain analysis helps in modeling the future land cover on the basis of the preceding state, i.e., a matrix of observed transition probabilities between states can be used for projecting future changes in the landscape from current patterns (Brown et al. 2000). The model is used to predict changes in LULC in different spatial scales. Use of Markov chain models in land use studies tend to focus usually on a much larger spatial scale, and it involves both urban and non-urban land covers (Robinson 1978; Muller and Middleton 1994). Markov chain modelling was also performed by taking sampled data from field surveys, existing maps, or aerial photography (Robinson 1978; Wu et al. 2006; Peterson et al. 2009).

The present study focuses on detecting the conversion of forests into step cultivation and builtup areas in Gangtok. The study also examines the stochastic nature of the LULC and predicts change in the near future. A hybrid approach, i.e., remote sensing based analysis and statistical modelling is adopted to assess the forest cover change using satellite image classification techniques. In this study, the Markov chain modeling was applied for prediction of future land cover for the year 2020 .

\section{Study area and datasets}

The study area, Gangtok, is situated in Sikkim, a subHimalayan state in eastern India (figure 1). The geographical location of the city is $27^{\circ} 20^{\prime} 08^{\prime \prime} \mathrm{N}$ and $88^{\circ} 36^{\prime} 44^{\prime \prime} \mathrm{E}$. It is situated at an altitude of $1680 \mathrm{~m}$ (approx.) and has an areal extent of about $25 \mathrm{~km}^{2}$. A buffer zone of $10 \mathrm{~km}$ was taken into consideration in this study, for assessment of probable futuristic urbanization. Due to the Lower Himalayan foothill location with a mild subtropical humid climate, Gangtok is the heart of the tourism industry of Sikkim. Gangtok enjoys a mild climate all over the year. Temperature ranges from $22^{\circ} \mathrm{C}$ in summer to $4^{\circ} \mathrm{C}$ in winter. Precipitation starts from May and intensifies in July-August. July receives the highest monthly average rainfall of $650 \mathrm{~mm}$. Temperatures below freezing and snowfall are very rare. Dense temperate deciduous forests are present in Gangtok and its surroundings. The main trees are poplar, birch, oak, and elm with abundant orchids and occasional tropical evergreen trees like bamboo. In the lower parts of the town, the vegetation changes from tropical deciduous to subtropical. Stepped cultivated land is a common land-use feature.

Landsat-TM and ETM+ multispectral imageries (path/row: 138/44) of three different years such as 1990, 2000, and 2010 were used for this study. The visible and near-infrared bands of these sensors were used for classification and spectral indices generation. The spatial resolution of the data is 30 $\mathrm{m}$ and all the datasets were projected to Universal Transverse Mercator projection with WGS 84 datum (zone number 45). The satellite imageries were co-registered with each other. The training sets were collected from the field using handheld GPS (figure 1). 


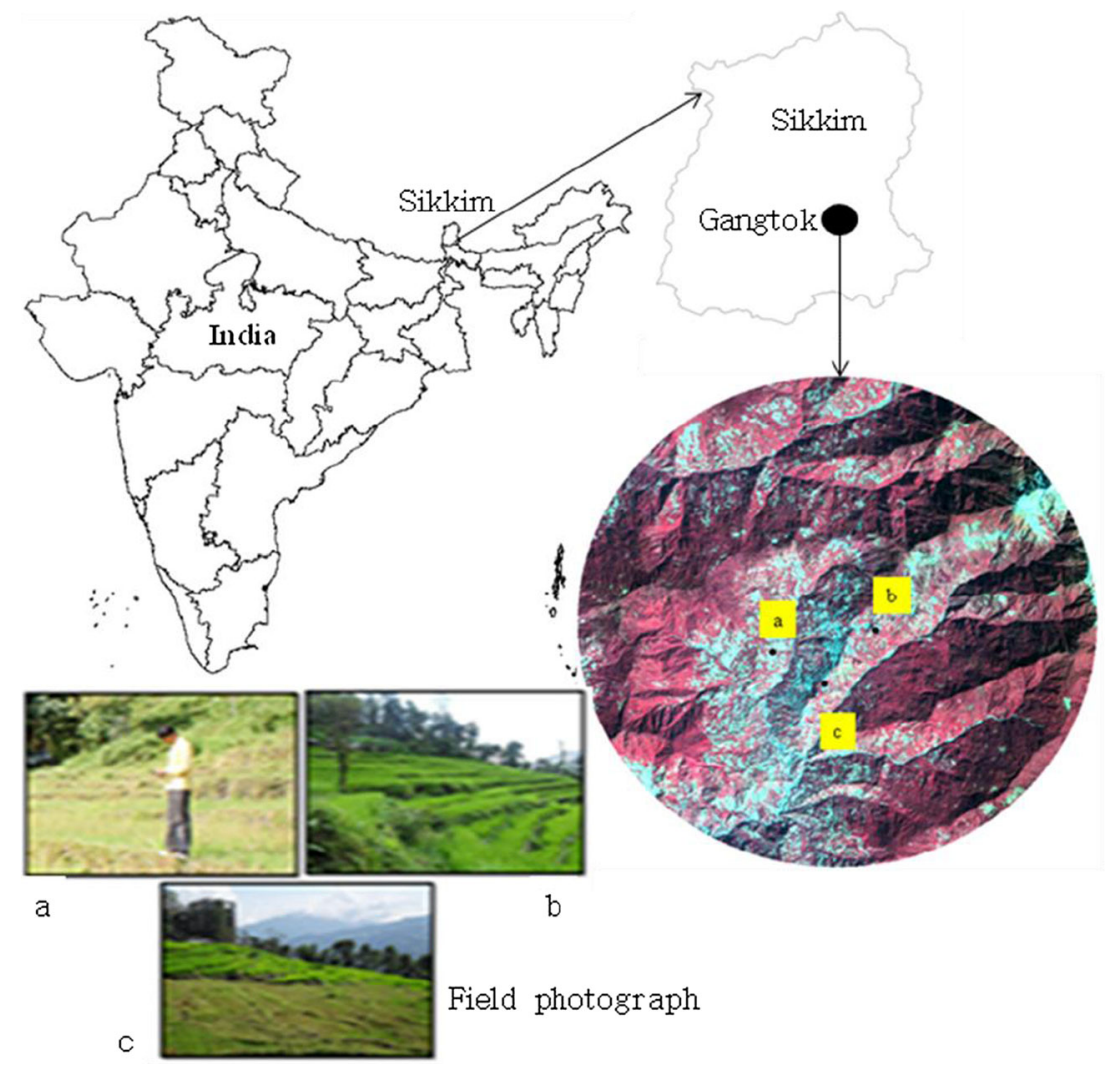

Figure 1. Location of the study area and field photograph.

\section{Methodology}

Each of the three satellite imageries was radiometrically and atmospherically corrected. Three major land-cover classes (built up area and bare land, step cultivated area, and forest) were extracted using the corrected satellite image by two techniques, i.e., supervised classification and spectral indices base thresholding using NDVI and SAVI. Accuracy assessment was done based on field data of the year 2010. Land use prediction was carried out by using Markov chain model for the year 2010 using classified imageries of the years 1990 and 2000. A comparison of predictions derived from different techniques was done with the actual scenario of the year 2010. The technique giving the closest result was used for the prediction of land cover changes for the year 2020. The methodology adopted in this study is given in a sequential manner (figure 2).

\subsection{Radiometric calibration and atmospheric correction}

Radiometric calibration of satellite data for classification and change detection from multi-temporal image is necessary for gain and bias correction
(Duggin and Robinove 1990). Radiometric calibration was carried out on satellite imageries prior to image classification and generation of spectral indices. The image derived Digital Number (DN) was converted back into at-sensor spectral radiance $\left(L_{\mathrm{TOA}}\right)$ by calibrating the data using sensor calibration equation (equation 1) (Chander and Markham 2003; Melesse 2004).

$$
\begin{aligned}
L_{\mathrm{TOA}}= & \left(\frac{L_{\max }-L_{\min }}{Q C A L_{\max }-Q C A L_{\min }}\right) \\
& \times\left(D N-Q C A L_{\min }\right)+L_{\min }
\end{aligned}
$$

where $L_{\mathrm{TOA}}$ is solar irradiance at top of the atmosphere, $L_{\max }$ and $L_{\min }$ are maximum and minimum radiance in $\mathrm{W} / \mathrm{m}^{-2} \mathrm{sr}^{-1} \mu \mathrm{m}^{-1}$. $Q C A L_{\max }$ and $Q C A L_{\min }$ are maximum and minimum $\mathrm{DN}$ values possible (255 or 1$)$. The calibration gain and offset $\left(L_{\max }\right.$ and $\left.L_{\min }\right)$ are available in the imagery header file.

Scattering effect is dominant for the Landsat data and moreover, for generation of spectral indices, atmospheric correction is necessary (Song et al. 2001). Dark Object Subtraction (DOS) image based atmospheric correction model given by Chavez (1996) was adopted for correcting the VNIR bands due to its simplicity 


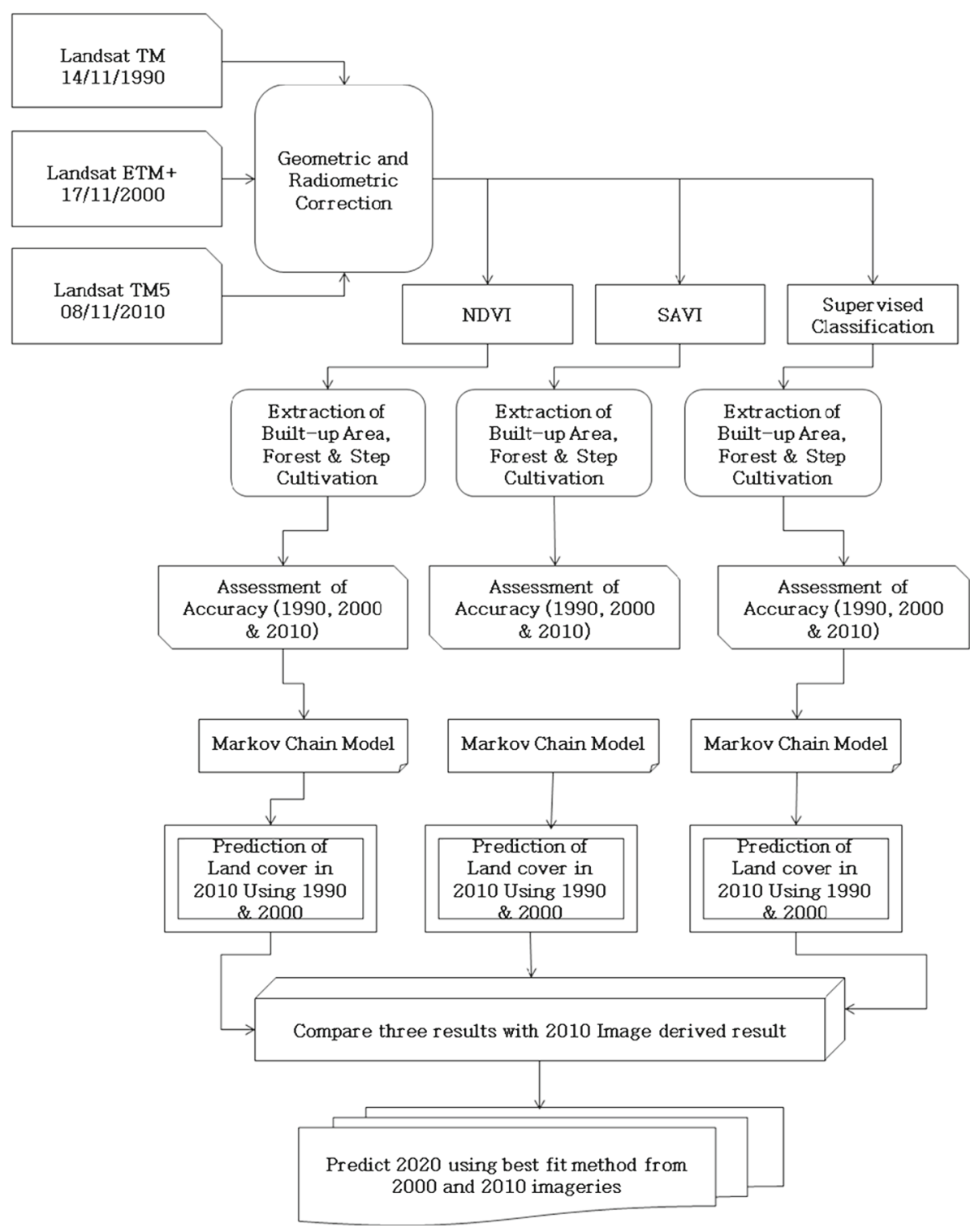

Figure 2. Flow chart showing the methodology adopted in this study.

and nonavailability of radiosounding data. Radiance value was converted into atmospherically corrected reflectance using the following equation (equation 2)

$$
\rho=\frac{\left(L_{\mathrm{TOA}}-L_{p}\right) \pi d^{2}}{E S U N_{\lambda} \cos \theta_{z} T_{z}}
$$

where $\rho$ is at surfaced reflectance, $d$ is Earth Sun distance (AU), $E S U N_{\lambda}$ is band pass solar irradiance at top of the atmosphere (TOA) taken from Landsat data user handbook, $\theta_{z}$ is solar zenith angle (deg) and $T_{Z}$ is atmospheric transmission between ground and TOA. The value of $T_{Z}$ for band 4 and 5 are taken as 0.85 and 0.95 , respectively (Chavez 1996). $L_{p}$ is radiance resulted with the interaction aerosol and atmospheric particles and estimated based on Song et al. (2001); Chavez
(1996) and Sobrino et al. (2004). The equation for calculation of $d$ and $L_{p}$ are follows:

$$
\begin{gathered}
d=1.001672 \times \operatorname{Sin}\left(\frac{2 \pi(J-93.5)}{365}\right) \\
L_{p}=L_{\min }-L_{1 \%} \\
L_{1 \%}=\frac{0.01 \cos \theta_{z} T_{z} E S U N}{\pi d^{2}}
\end{gathered}
$$

\subsection{Image classification and land cover map generation}

In order to carry out the vegetation cover change, the satellite imageries of 1990, 2000, and 2010 were 
converted into thematic land cover using supervised classification by Maximum Likelihood Classifier (MLC) and spectral indices based thresholding of corrected satellite imageries. As the study mainly concentrates on the analysis of vegetation cover change, first level classification was performed and three major land cover classes (built up area and bare land, step cultivated area, and forest) were considered. The initial five bands of Landsat TM and ETM+ were considered for classification. The training sets were collected from the field using handheld GPS.

The amount of light reflected from a surface is a function of its internal properties, along with the amount and intensity of the incoming radiation. As the solar radiation varies over time and also with atmospheric condition, a simple measure of light is often not sufficient for accurate level of classification. This problem is often rectified by combining the data from two spectral bands to form vegetation indices and to achieve enhanced signal of the vegetation cover by minimizing solar radiation and soil background effects (Jackson and Huete 1991). For this reason, spectral indices are very useful to classify the land cover. The differential illumination effects in various slopes are reduced due to band rationing so that accurate identification of land cover can be achieved. Well practiced NDVI was used in this study. It uses the difference in reflectance between near infrared (NIR) and red band normalized by sum of NIR and red reflectance (Rouse et al. 1974) (equation 6).

$$
\mathrm{NDVI}=\frac{\rho_{\mathrm{NIR}}-\rho_{\mathrm{Red}}}{\rho_{\mathrm{NIR}}+\rho_{\mathrm{Red}}} .
$$

It is the most widely used vegetation index for its high sensitivity with the presence of vegetation and its state (Zhang et al. 2006), and can eliminate the effects of sun angle, view angle, and atmospheric effects up to $6 \%$ (Zhao 2003). Moreover, NDVI has a good relationship with other biophysical parameters like Leaf Area Index and vegetation cover (Huete et al. 1997; Gong et al. 2003). The threshold values for built up area and bare land, step cultivated area and forest LULC are $<0.2,0.2-0.5$ and $>0.5$, respectively. Threshold value is derived based on NDVI image and with the help of spatial profiling study.

But it was found in the previous studies (Huete 1988; Chen 1996) that the soil characteristics affect the NDVI calculation, especially when bare soils are present. The study area considered in the present work is characterized by stepped farming with large extent of bare soil, which is likely to affect the reflectance. To eliminate this effect,
Huete (1988) proposed Soil Adjusted Vegetation Index (SAVI) (equation 7).

$$
\mathrm{SAVI}=\frac{\rho_{\mathrm{NIR}}-\rho_{\mathrm{Red}}}{\rho_{\mathrm{NIR}}+\rho_{\mathrm{Red}}+L}(1+L)
$$

where $L=$ soil adjustment factor, which in the case of SAVI was kept at 0.5 (Huete 1988). Hence, SAVI based thresholding has also been used to classify the land cover. Similar threshold value such as $<0.2$ for built up area and bare land, 0.2-0.5 for step cultivated area, and $>0.5$ for forest cover were taken. The threshold is study area specific and needs to be derived from the image.

Satellite imageries of 1990, 2000 and 2010 were classified and validated using error matrix and Kappa statistics. Error matrix is considered as one of the common techniques for measuring the accuracy of thematic map (Smits et al. 1999). It measures a sample from a particular category of the classified map and the actual category can be verified from the ground or reference data (Congalton 1991).

\subsection{Markov chain modelling for future prediction}

Markov chain model analyzes two qualitative landcover images of different dates (Moghadam and Helbich 2013) and produces a transition probability matrix, a transition area matrix, and a set of conditional probability images (Guana et al. 2011; Tang et al. 2007). The transition matrix is the probability that each land cover category will change to every other category. Transition area matrix records the number of pixels that are expected to change from each land-cover type to other land-cover type over the specified number of time units. The model also provides a set of conditional probability images for each land-cover class. These maps express the probability that each pixel will belong to the designated class in the next time period. They are called conditional probability maps, since this probability is conditional on their current state. Those conditional probability images can produce a number of potential realizations of the projected changes within the conditional probability maps. To improve the spatial sense of these conditional probability images using redistribute of the statistic such that it follows the suggested pattern, but maintains the overall area total.

Markov chain model is used to predict future changes by considering land-cover classes derived from the satellite data and evaluating the future projection within a span of 20 years (1990-2010 and 2000-2020). In the Markov chain model, usually, land-cover change is considered to be a stochastic process and diverse classes are 
considered in the states of a chain. Also, a chain can be identified as a stochastic process at time $t$, $X_{t}$, depending on value at time $t-1, X_{t-1}$, and not depending on the series of values like $X_{t-2}, X_{t-3}$, $\ldots, X_{0}$, so that the process passed in the course in arriving at $X_{t-1}$ (Weng 2002) (equation 8):

$$
\begin{gathered}
P\left\{X_{t}=a_{j} \mid X_{0}=a_{0}, X_{1}=a_{1}, \ldots, X_{t-1}=a_{i}\right\} \\
=P\left\{X_{t}=a_{j} \mid X_{t-1}=a_{i}\right\} .
\end{gathered}
$$

Moreover, it is appropriate for the change process as one that is uniquely distinct with time $(t=0$, $1,2, \ldots)$.

The $P\left\{X_{t}=a_{j} \mid X_{t-1}=a_{i}\right\}$ is recognized as the one-step transitional probability, which gives the possibility of creating the transition from state $a_{i}$ to state $a_{j}$ in between one time period. When $l$ steps are necessary to implement this transition, the $P\left\{X_{t}=a_{j} \mid X_{t-1}=a_{i}\right\}$ is then called the $l$ step transition probability, $P_{i j}^{(l)}$.
When $P_{i j}^{(l)}$ is time independent and is dependent only on the states $a_{i}, a_{j}$ and $l$, then Markov chain is regarded as homogeneous. Here in equation (9),

$$
P\left\{X_{t}=a_{j} \mid X_{t-1}=a_{i}\right\}=P_{i j}
$$

where $P_{i j}$ is acquired from the data observed, after arrangement of the number of times the observed data goes from state $i$ to $j, n_{i j}$, and the number of occurrences of the state $a_{i}, n_{i}$ is summed up. Then in equation (10),

$$
P_{i j}=\frac{n_{i j}}{n_{i}}
$$

As the Markov chain proceeds, probability of maintaining in state $j$ gets independent of the initial state of the chain after many steps. When this condition is arrived, the chain is believed to have attained a steady state. Then $P_{j}$, i.e., the limit
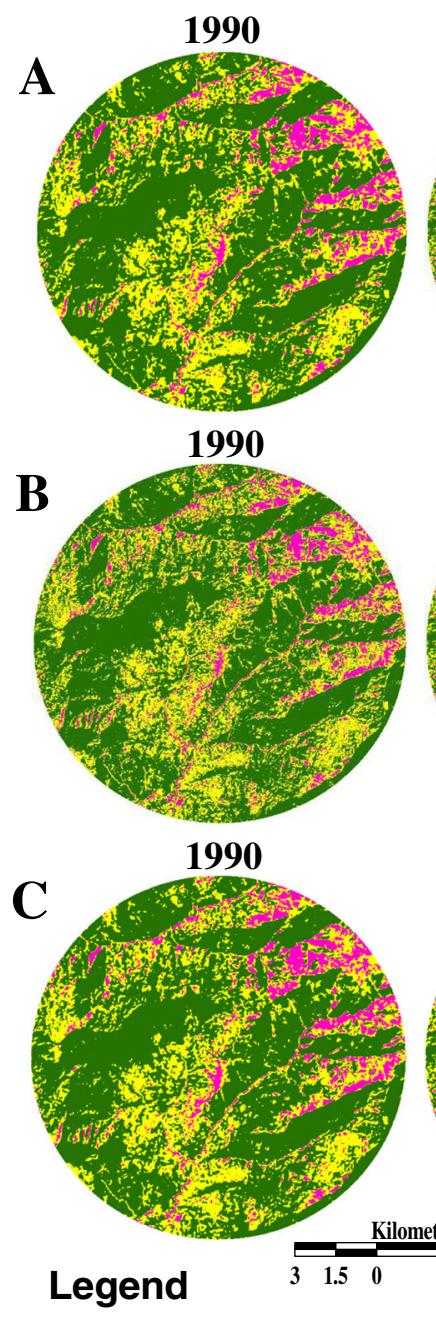

Built-up area

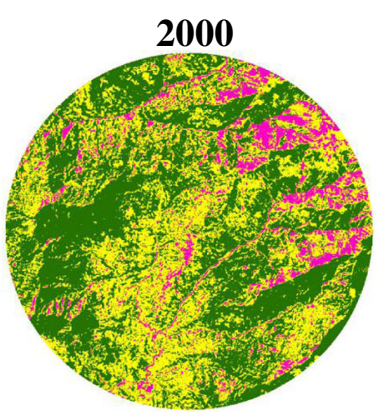

2000
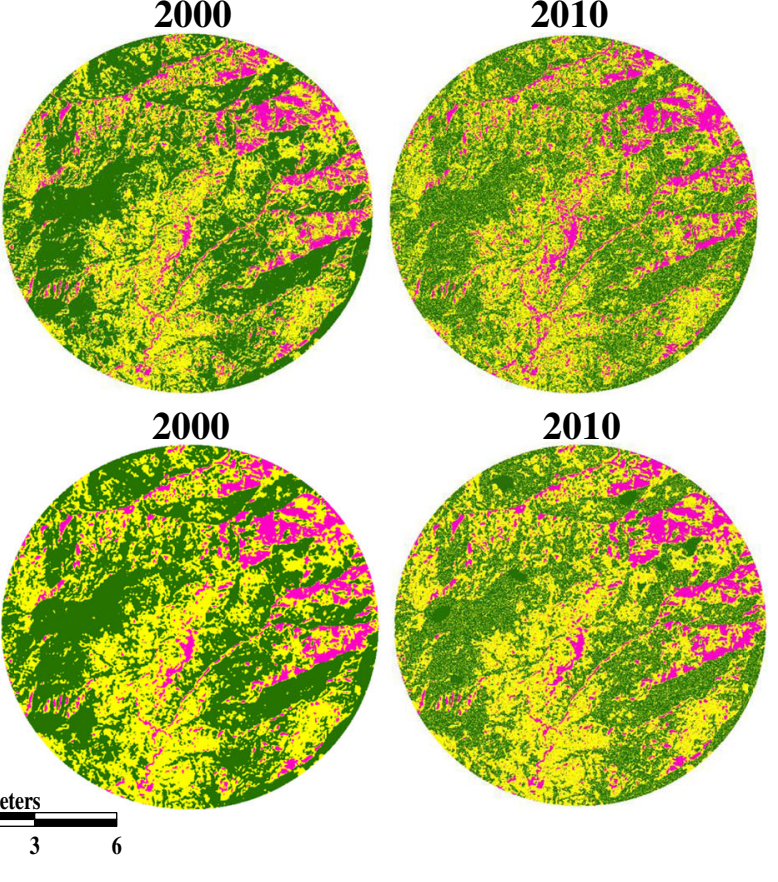

Figure 3. Classification of land use/land cover in Gangtok city and its surroundings in 1990 to 2010 using (a) MLC classification, (b) NDVI, and (c) SAVI. 
probability, is applied for the determination of the value of $P_{i j}^{(l)}$, (equation 11)

$$
\lim _{n} P_{i j}^{(n)}=P_{j}
$$

where $P_{j}=P_{i} P_{i j}^{(n)}, j=1,2, \ldots, m$ (state), $P_{i}=1$ and $P_{j}>0$.
In case of transition probability matrix, each of the elements consist of a category with observed and expected number of transitions (equation 12)

$$
\chi^{2}=\sum \frac{(O-E)^{2}}{E} .
$$

Table 1. Land use/land cover status of Gangtok city between 1990 and 2010 using maximum likelihood classification, NDVI and SAVI based thresholding.

\begin{tabular}{llccc}
\hline $\begin{array}{l}\text { Classification } \\
\text { techniques }\end{array}$ & $\begin{array}{c}\text { Land use/land cover } \\
\text { classes }\end{array}$ & $\begin{array}{c}\text { Area in 1990 } \\
\left(\mathrm{km}^{2}\right)\end{array}$ & $\begin{array}{c}\text { Area in 2000 } \\
\left(\mathrm{km}^{2}\right)\end{array}$ & $\begin{array}{c}\text { Area in 2010 } \\
\left(\mathrm{km}^{2}\right)\end{array}$ \\
\hline MLC & Built-up and bare land & 25.82 & 29.75 & 34.79 \\
& Step cultivation & 84.45 & 115.67 & 140 \\
& Forest & 189.20 & 154.05 & 124.68 \\
NDVI & Built-up and bare land & 24.50 & 29.70 & 34.91 \\
& Step cultivation & 83.51 & 115.74 & 128.60 \\
& Forest & 191.46 & 154.03 & 135.95 \\
SAVI & Built-up and bare land & 25.93 & 29.44 & 35.11 \\
& Step cultivation & 84.49 & 117.13 & 139.53 \\
& Forest & 189.05 & 152.90 & 124.83 \\
\hline
\end{tabular}

\begin{tabular}{|c|c|c|c|c|}
\hline $\begin{array}{l}\text { Classification } \\
\text { techniques }\end{array}$ & Year & $\begin{array}{c}\text { Land use/land cover } \\
\text { classes }\end{array}$ & $\begin{array}{c}\text { Producer's } \\
\text { accuracy }(\%)\end{array}$ & $\begin{array}{c}\text { User's } \\
\text { accuracy }(\%)\end{array}$ \\
\hline \multirow[t]{9}{*}{ MLC } & \multirow[t]{3}{*}{1990} & Built-up and bare land & 85.71 & 85.71 \\
\hline & & Step cultivation & 74.07 & 83.33 \\
\hline & & Forest & 92.16 & 87.04 \\
\hline & \multirow[t]{3}{*}{2000} & Built-up and bare land & 75 & 75 \\
\hline & & Step cultivation & 82.35 & 84.85 \\
\hline & & Forest & 88.37 & 86.36 \\
\hline & \multirow[t]{3}{*}{2010} & Built-up and bare land & 80 & 80 \\
\hline & & Step cultivation & 84.38 & 87.10 \\
\hline & & Forest & 90.70 & 88.64 \\
\hline \multirow[t]{9}{*}{ NDVI } & \multirow[t]{3}{*}{1990} & Built-up and bare land & 75 & 85.71 \\
\hline & & Step cultivation & 76.92 & 80 \\
\hline & & Forest & 88.24 & 84.91 \\
\hline & \multirow[t]{3}{*}{2000} & Built-up and bare land & 77.78 & 87.50 \\
\hline & & Step cultivation & 84.85 & 84.85 \\
\hline & & Forest & 88.37 & 86.36 \\
\hline & \multirow[t]{3}{*}{2010} & Built-up and bare land & 80 & 80 \\
\hline & & Step cultivation & 83.78 & 86.11 \\
\hline & & Forest & 86.84 & 84.62 \\
\hline \multirow[t]{9}{*}{ SAVI } & \multirow[t]{3}{*}{1990} & Built-up and bare land & 85.71 & 85.71 \\
\hline & & Step cultivation & 79.17 & 79.17 \\
\hline & & Forest & 88.89 & 88.89 \\
\hline & \multirow[t]{3}{*}{2000} & Built-up and bare land & 75 & 75 \\
\hline & & Step cultivation & 85.29 & 87.88 \\
\hline & & Forest & 90.70 & 88.64 \\
\hline & \multirow[t]{3}{*}{2010} & Built-up and bare land & 80 & 80 \\
\hline & & Step cultivation & 89.74 & 87.50 \\
\hline & & Forest & 86.11 & 88.57 \\
\hline
\end{tabular}

Table 2. Accuracy assessment of maximum likelihood classification, NDVI and SAVI. 
Here $O$ is regarded as the observed number of transitions from one state to another and $E$ is considered as the expected number of transition, in case, the successive states are independent.

Initially, land cover prediction was done for the year 2010 considering the 1990 and 2000 datasets and was validated using actual classified land cover of 2010. Finally, land cover prediction was done for the year 2020 .

Table 3. Kappa statistics for the three land use classes from 1990 to 2010 using maximum likelihood classification method, NDVI and SAVI.

\begin{tabular}{lcccc}
\hline Class names & Years & MLC & NDVI & SAVI \\
\hline Built-up and & 1990 & 0.84 & 0.84 & 0.84 \\
bare land & 2000 & 0.72 & 0.86 & 0.72 \\
& 2010 & 0.77 & 0.77 & 0.77 \\
Step cultivation & 1990 & 0.76 & 0.71 & 0.70 \\
& 2000 & 0.75 & 0.75 & 0.80 \\
& 2010 & 0.79 & 0.75 & 0.77 \\
Forest & 1990 & 0.68 & 0.62 & 0.70 \\
& 2000 & 0.72 & 0.72 & 0.77 \\
& 2010 & 0.77 & 0.72 & 0.80 \\
\hline
\end{tabular}

Table 4. Overall accuracy of the three classification techniques.

\begin{tabular}{lcccr}
\hline Particulars & Years & MLC & NDVI & SAVI \\
\hline Overall Kappa & 1990 & 0.73 & 0.69 & 0.72 \\
statistics & 2000 & 0.73 & 0.76 & 0.77 \\
& 2010 & 0.78 & 0.74 & 0.78 \\
& & & & \\
Overall accuracy & 1990 & 85.88 & 83.53 & 85.88 \\
(in \%) & 2000 & 84.71 & 85.88 & 87.06 \\
& 2010 & 86.16 & 84.71 & 87.06 \\
\hline
\end{tabular}

\section{Result and discussions}

In this study the results are reported in three sections land use/land cover classification, accuracy assessment, and land use/land cover prediction and validation. The Markov chain model predicted future land cover is validated for the year 2010 and a projected land cover for the year 2020 is estimated.

\subsection{Land use/land cover classification}

Atmospherically corrected imageries of 1990, 2000, and 2010 were classified and divided into three classes such as built up area and bare land, step cultivated area, and forest. The LULC results of MLC classification and spectral indices (NDVI and SAVI) based thresholding are shown in figure 3.

The classification result shows the significant decrease of forest since 1990. The area under each LULC was calculated and it was observed that the areas under stepped cultivation and settlements are increasing, with time, at the expense of the forest cover (table 1).

Table 5. Land use/land cover prediction and validation for 2010 based on the three classification techniques.

\begin{tabular}{|c|c|c|c|c|}
\hline $\begin{array}{l}\text { Classification } \\
\text { techniques }\end{array}$ & & $\begin{array}{c}\text { Built-up and } \\
\text { bare land } \\
\left(\mathrm{km}^{2}\right)\end{array}$ & $\begin{array}{c}\text { Step } \\
\text { cultivation } \\
\left(\mathrm{km}^{2}\right)\end{array}$ & $\begin{array}{l}\text { Forest } \\
\left(\mathrm{km}^{2}\right)\end{array}$ \\
\hline \multirow[t]{2}{*}{ MLC } & Actual & 34.79 & 140 & 124.68 \\
\hline & Predicted & 37.68 & 145.91 & 115.88 \\
\hline \multirow[t]{2}{*}{ NDVI } & Actual & 34.91 & 128.60 & 135.96 \\
\hline & Predicted & 36.79 & 132.77 & 129.91 \\
\hline \multirow[t]{2}{*}{ SAVI } & Actual & 35.11 & 139.53 & 124.83 \\
\hline & Predicted & 36.25 & 142.30 & 120.92 \\
\hline
\end{tabular}

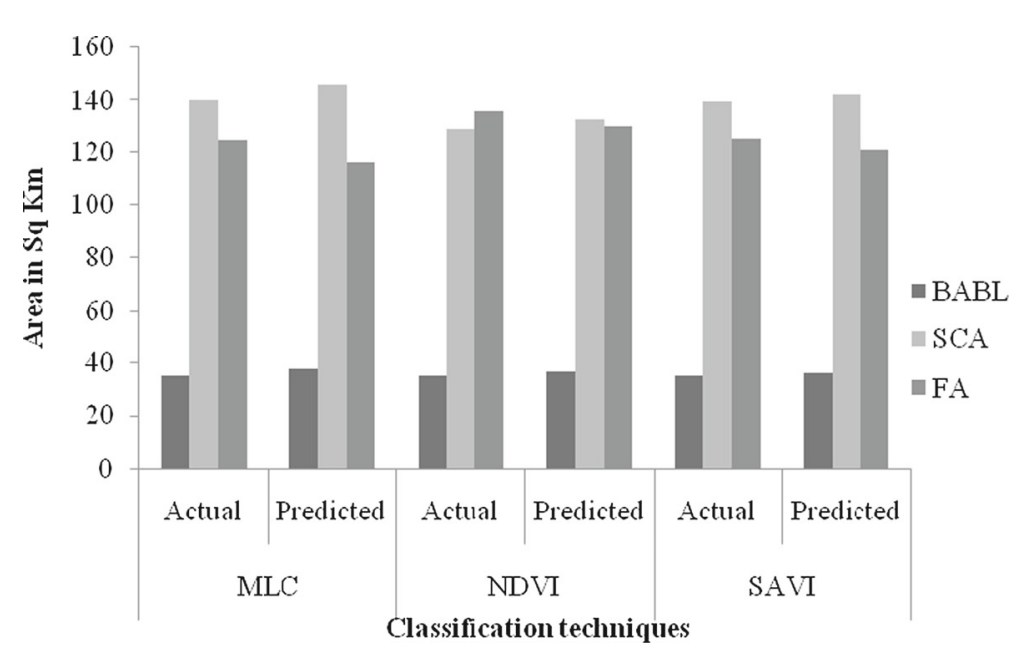

Figure 4. Showing actual and predicted land use/land cover for the year 2010 in Gangtok and its surroundings using (a) MLC classification, (b) NDVI, and (c) SAVI. 
Step cultivation has increased very rapidly in 20 years. The major change is found in the central, south, and eastern parts of the study area. Analysis of the results obtained from MLC classification indicates that the forest cover has declined by $34 \%$ from 1990 to 2010, but the step cultivation and built-up areas have increased by almost $35 \%$ and $66 \%$, respectively. NDVI analysis shows that the forest cover has declined by almost 30\% during the period of study. Relative to that, stepped cultivated and built-up areas have increased by $54 \%$ and $43 \%$, respectively. In the case of SAVI classification, results suggest that the area under forest has declined by almost $35 \%$ in 20 years while builtup and stepped cultivation areas have increased by $35.4 \%$ and $65 \%$, respectively. The decrease of forested land is an important aspect in Gangtok and its surrounding areas due to the hilly terrain conditions. It can cause landslides which are a threat to the environment and economy.

\subsection{Accuracy assessment}

Error matrix was prepared for the calculation of producers' and users' accuracy using 85 sample points generated using the stratified random sampling method with the corresponding reference points for all the three techniques. The accuracy assessment results of MLC, NDVI and SAVI based thresholding are shown in table 2.

Kappa statistics signifies the strength of agreement between observed and classified data (Landis and Koch 1977). Kappa statistics for the three techniques used in this study is shown in table 3 . It shows that for the three classes in 2010, the Kappa values are $0.77,0.79$, and 0.77 , respectively for MLC classification; 0.77, 0.75, and 0.72, respectively for NDVI and $0.77,0.77$, and 0.80 , respectively for SAVI. When Kappa-value of the classified result falls under $0.61-0.80$, it means that the strength of agreement is substantial (Landis and Koch 1977). The overall accuracy achieved from 2010 image is $86.16 \%$ for MLC, $84.71 \%$ for NDVI and $87.06 \%$ for SAVI (table 4 ).

\subsection{Land use/land cover of 2010: prediction and validation}

The predicted land use/land cover results of Markov chain model of 2010 (using 1990 and 2000 classified map) by three methods adopted in this study were compared to find out the best possible

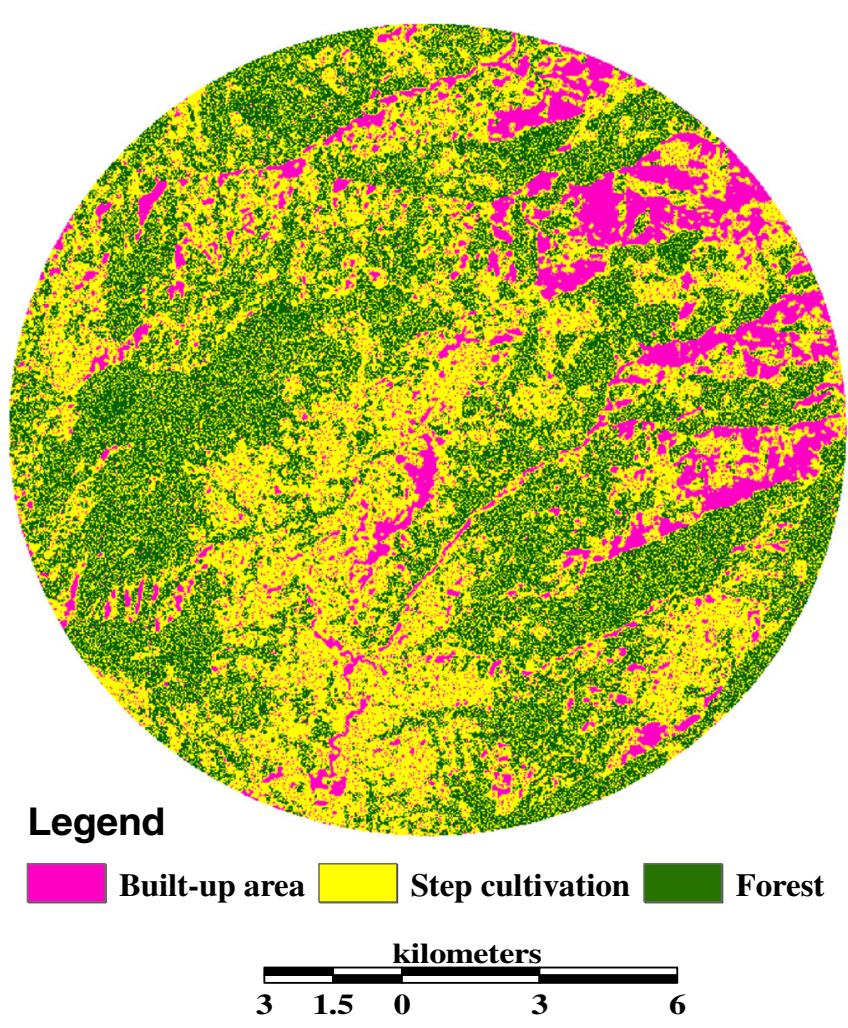

Figure 5. Land use/land cover scenario in the environments of Gangtok in 2020 (projected) by Markov chain modelling.

Table 6. Land use/land cover change matrix.

\begin{tabular}{clccc}
\hline \multirow{2}{*}{2000} & & $\begin{array}{c}\text { Built-up and } \\
\text { bare land }\end{array}$ & $\begin{array}{c}2010 \\
\text { Step cultivation }\end{array}$ & Forest \\
\hline \multirow{2}{*}{$\begin{array}{l}\text { Built-up and bare land } \\
\text { Step cultivation }\end{array}$} & 28.93 & 0.51 & 0.00 \\
Forest & 5.25 & 111.87 & 0.001 \\
& & 2.07 & 29.92 & 120.91 \\
\hline
\end{tabular}

Table 7. Transitional probability matrix of land use/land cover change.

\begin{tabular}{clccc}
\hline \multirow{2}{*}{$2000 \quad \begin{array}{c}\text { Built-up and } \\
\text { bare land }\end{array}$} & $\begin{array}{c}2010 \\
\text { Step cultivation }\end{array}$ & Forest \\
\hline \multirow{2}{*}{$\begin{array}{l}\text { Built-up and bare land } \\
\text { Step cultivation }\end{array}$} & 0.98 & 0.01 & 0.00 \\
Forest & 0.04 & 0.95 & 0.001 \\
& & 0.01 & 0.19 & 0.79 \\
\hline
\end{tabular}


Table 8. Land use/land cover change matrices for 2010 and 2020 predictions based on $S A V I$

\begin{tabular}{rlcrr}
\hline & & $\begin{array}{c}\text { Built-up and } \\
\text { bare land }\end{array}$ & $\begin{array}{c}2020 \\
\text { Step cultivation }\end{array}$ & Forest \\
\hline \multirow{3}{*}{$2010 \quad\left\{\begin{array}{llr}\text { Built-up and bare land } \\
\text { Step cultivation }\end{array}\right.$} & 35.03 & 0.08 & 0.00 \\
& Forest & 4.75 & 134.51 & 0.27 \\
& & 2.06 & 21.18 & 101.59 \\
\hline
\end{tabular}

Table 9. Transition probability matrices for 2010 and 2020 predictions based on SAVI.

\begin{tabular}{clccc}
\hline & & $\begin{array}{c}\text { Built-up and } \\
\text { bare land }\end{array}$ & $\begin{array}{c}2020 \\
\text { Step cultivation }\end{array}$ & Forest \\
\hline \multirow{2}{*}{$2010 \quad\left\{\begin{array}{llc}\text { Built-up and bare land } \\
\text { Step cultivation }\end{array}\right.$} & 0.99 & 0.002 & 0.00 \\
& Forest & 0.03 & 0.96 & 0.002 \\
& & 0.01 & 0.16 & 0.81 \\
\hline
\end{tabular}

method that matches with the real time changes during 2000-2010. The results obtained were then validated against the actual scenario (figure 4 ). It was found that the Markov chain model is very close to the actual result and the SAVI-based prediction provides highest similarity compared to other methods (table 5). The change matrix of LULC and transitional probability were calculated and shown in tables 6 and 7. A considerable area under forest land has been converted into step cultivated area and built-up land. Forest area has the lowest transitional probability. It indicates that due to increase in population density and urbanisation process, as well as industrialization, deforestation has taken place in the Gangtok. The increase in step cultivation and reduction in forest cover can cause soil erosion, landslides, and environmental degradation.

\subsection{Land use/land cover prediction for 2020}

The validation result shows that SAVI based thresholding gives the most accurate estimation of land use and land cover. Hence, land cover map of 2000 and 2010 based on SAVI thresholding were used to estimate the projected land use for the year 2020 by Markov chain modelling. The predicted LULC has been shown in figure 5. The predicted LULC signifies that Gangtok city will expand gradually in the north and northeast direction from the main city. Intensity of built-up area will increase in the residential area and spread to the outer side of the city. Some patches of built-up area will develop in the northwest, south and southeastern part. The forest will be reduced mainly in the central and southern parts, which will be converted into step cultivable land. In the southeastern and northeastern sides, step cultivable land will be significantly increased. The projected areas (2020) under built-up and bare land, step cultivation, and forest are 41.84, 155.77, and $101.86 \mathrm{~km}^{2}$, respectively. It shows a significant increase in step cultivation $\left(16.27 \mathrm{~km}^{2}\right)$ and built-up area $\left(6.74 \mathrm{~km}^{2}\right)$, compared to 2010. A significant reduction of forest area $\left(22.94 \mathrm{~km}^{2}\right)$ is found. Reduction in forest areas is of great environmental significance. Also, in the hilly areas, deforestation may cause landslides. Although, in general, it is difficult to relate landslide occurrences to land-use changes (Glade 2003), case studies in New Zealand could establish explicit relationship between landslide events and anthropogenic land-use changes, particularly deforestation (O'Loughlin and Pearce 1976; Crozier et al. 1978; Page et al. 1994a, b; Page and Trustrum 1997). The change matrix (table 8) shows the possibility of higher transition from forest to step cultivation in 2020. Moreover, significant increase may occur in built-up and bare land area.

Table 9 shows the transitional probability matrices for 2010 and 2020. The diagonal of the transition probability matrix represents the selfreplacement probabilities whereas the off-diagonal values indicate the probability of change occurring from one state to another state or class. The transitional probability matrix shows that built-up and bare land area is the highest consistent land cover because the probability value is 0.99 . The self-replacement probability of forest class is very less, i.e., 0.81. It also shows the high probability of transition between forests to step cultivation. This signifies that there is a high probability of forest being converted into step cultivation and step cultivation being converted into built-up and bare land by 2020 .

\section{Conclusion}

Gangtok, the state capital of Sikkim is experiencing rapid urbanization. Besides, it has also become the main hub of the tourism industry for the 
region. This requires large scale expansion of builtup areas, mostly at the cost of forested and cultivated areas. Since the tourism industry is seasonal in nature, and cannot serve all the stakeholders, the people residing here have to depend on agriculture to derive their livelihood. In a mountainous terrain like Gangtok, stepped cultivation is the only possible means of agriculture and it takes place through deforestation. As a result, there is an increase in the number of landslides in this region.

The reduction of forest cover and the increase in built-up and step cultivated area are well reflected in the satellite imageries of the study period. Future land use/land cover prediction using Markov modelling suggests that the scenario would only worsen in the near future. Therefore, it is imperative that the state government of Sikkim provide a solution to this problem, so that Gangtok city and its surrounding environments can be saved from more catastrophic landslides in the future. Analysis of satellite data has shown considerable reduction of forest cover in the Gangtok area during the past 20 years. Stepped cultivation is responsible for a substantial part of this transformation. Markov modelling shows that by 2020, more forested areas will be converted into step cultivated areas.

\section{References}

Alcorn J B 1993 Indigenous peoples and conservation; Conservation Biology 7 424-426.

Allen J C and Barnes D F 1985 The causes of deforestation in developing countries; Ann. Assoc. Am. Geogr. 75 163-184.

Balick M J 1990 Ethnobotany and the identification of therapeutic agents from the rainforest; In: Bioactive compounds from plants (eds) Chadwick D J and Marsh J, John Wiley \& Sons, Chichester, pp. 22-31.

Bradshaw C J A, Sodhi N S, Peh K S H and Brook B W 2007 Global evidence that deforestation amplifies flood risk and severity in the developing world; Glob. Change Biol. 13 2379-2395.

Brown D G, Pijanowski B C and Duh J D 2000 Modeling the relationships between land use and land cover on private lands in the Upper Midwest, USA; J. Environ. Manag. $59247-263$.

Bruijnzeel L A 2004 Hydrological function of tropical forests: Not seeing the soil for the trees; Agriculture, Ecosystems and Environment 104 185-228.

Chakraborty M 1994 An analysis of the causes of deforestation in India; In: The causes of tropical deforestation: The economic and statistical analysis of factors giving rise to the loss of the tropical forests (eds) Brown K and Pearce D W (London: UCL Press), pp. 226-238.

Chander G and Markham B 2003 Revised Landsat-5 TM radiometric calibration procedures and post-calibration dynamic ranges; IEEE Trans. Geosci. Remote Sens. 41 2674-2677.

Chavez P S 1996 Image-based atmospheric correctionsrevisited and improved; Photogramm. Eng. Remote Sens. 62 1025-1036.
Chen J M 1996 Evaluation of vegetation indices and a modified simple ratio for Boreal applications; Canadian J. Remote Sens. 22 229-242.

Chen Y B, Zhou Q Y and Chen J F 2009 Spatiotemporal characteristics of land use and cover change in GuangZhou City in the past 30 years; Scientia Geographica Sinica 29(3) 368-374.

Crozier M J, Eyles R J and Wheeler R H 1978 Landslips in Wellington city; New Zealand Geographer 34 58-74.

Congalton R G 1991 A review of assessing the accuracy of classifications of remotely sensed data; Remote Sens. Environ. 37 35-46.

Dietzel C, Oguz H, Hemphill J J, Clarke K C and Gazulis N 2005 Diffusion and coalescence of the Houston Metropolitan Area: Evidence supporting a new urban theory; Environment and Planning B: Planning and Design 32 $231-246$.

Duggin M J and Robinove C J 1990 Assumptions implicit in remote sensing data acquisition and analysis; Int. J. Remote Sens. 11 1669-1694.

FAO 2010 Global forest resources assessment 2010: Main report; Rome, Food and Agricultural Organization, http://www.fao.org/docrep/013/i1757e/i1757e.pdf.

Glade T 2003 Landslide occurrence as a response to land use change: A review of evidence from New Zealand; Catena 51 297-314.

Guana D, Li H, Inohaec T, Su W, Nagaiec T and Hokao K 2011 Modeling urban land use change by the integration of cellular automaton and Markov model; Ecol. Model. 222 3761-3772, doi: 10.1016/j.ecolmodel.2011.09.009.

Gong P, Pu R, Biging G S and Larrieu M R 2003 Estimation of forest leaf area index using vegetation indices derived from Hyperion hyperspectral data; IEEE Trans. Geosci. Remote Sens. 41 1355-1362.

He C Y, Shi P J, Chen J and Zhou Y Y 2000 A study on landuse/cover change in Beijing area; Geogr. Res. 20(6) 679-687.

Herold M, Goldstein N C and Clarke K C 2003 The spatiotemporal form of urban growth: Measurement, analysis and modelling; Remote Sens. Environ. 86(3) 286302.

Huete A R 1988 A soil-adjusted vegetation index (SAVI); Remote Sens. Environ. 25 295-309.

Huete A R, Liu H Q, Batchily K and van Leeuwen W 1997 A comparison of vegetation indices over a global set of TM images for EOS-MODIS; Remote Sens. Environ. 59 440-451.

Jackson R D and Huete A R 1991 Interpreting vegetation indices; Preventive Veterinary Medicine 11 185-200.

Landis J R and Koch G G 1977 The measurement of observer agreement for categorical data; In: Biometrics, 33.

Laurance W F 1999a Gaia's lungs: Are the rainforests inhaling earth's excess carbon dioxide?; Natural History 108 96.

Laurance W F 1999b Reflections on the tropical deforestation crisis; Biological Conservation 91 109-117.

Liu H and Zhou Q 2005 Establishing a multivariate spatial model for urban growth prediction using multi-temporal images; Computers, Environment and Urban Systems 29(5) 580-594.

Masek J G, Lindsa F E and Goward S N 2000 Dynamics of urban growth in the Washington DC metropolitan area, 1973-1996, from Landsat observations; Int. J. Remote Sens. 21 3473-3486.

Melesse A M 2004 Spatiotemporal dynamics of land surface parameters in the Red River of North Basin; Physics and Chemistry of the Earth $A / B / C 29$ 795-810.

Miller R B and Small C 2003 Cities from space: Potential applications of remote sensing in urban environmental 
research and policy; Environmental Science $\mathscr{G}$ Policy 6 129-137.

Moghadam H S and Helbich M 2013 Spatiotemporal urbanization processes in the megacity of Mumbai, India: A Markov chains-cellular automata urban growth model; Appl. Geogr. 40 140e149, doi: 10.1016/j.apgeog. 2013.01.009.

Mollicone D, Achard F, Federici F, Eva H D, Grassi G, Belward A, Raes F, Swufert G, Stibig H-J, Matteucci G and Schulze E-D 2007 An incentive mechanism for reducing emissions from conversion of intact and non-intact forests; Climatic Change 83 477-493.

Muller R M and Middleton J 1994 A Markov model of land-use change dynamics in the Niagara region, Ontario, Canada; Landscape Ecology 9 151-157.

Myers N 1994 Tropical deforestation: Rates and patterns; In: The causes of tropical deforestation: The economic and statistical analysis of factors giving rise to the loss of the tropical forests (eds) Brown K and Pearce D W (London: UCL Press), pp. 27-40.

O'Loughlin C L and Pearce A J 1976 Influence of Cenozoic geology on mass movement and sediment yield response to forest removal, north Westland, New Zealand; Bull. Int. Assoc. Eng. Geo. 14 41-46.

Page M J and Trustrum N A 1997 A late Holocene lake sediment record of the erosion response to land use change in a steepland catchment, New Zealand; Zeitschrift für Geomorphologie N.F. 41 369-392.

Page M J, Trustrum N A and Dymond J R 1994a Sediment budget to assess the geomorphic agent of a cyclonic storm, New Zealand; Geomorphology 9 169-188.

Page M J, Trustrum N A and DeRose R C 1994b A high resolution record of storm induced erosion from lake sediments, New Zealand; J. Palaeolimnol. $11333-$ 348 .

Pal M and Mather P M 2004 Assessment of the effectiveness of support vector machines for hyperspectral data; Future Generation Computer Systems 20(7) 12151225.

Peterson L K, Bergen K M, Brown D G, Vashchuk L and Blam Y 2009 Forested land-cover patterns and trends over changing forest management eras in the Siberian Baikal region; Forest Ecol. Manag. 257 911-922.

Phillips O L, Malhi Y, Higuchi N, Laurance W F, Nunez P, Vasquez R, Laurance S, Ferreira L, Stern M, Brown S and Grace J 1998 Changes in the carbon balance of tropical forests: Evidence from long-term plots; Science $\mathbf{2 8 2}$ 439-442.

Robinson V B 1978 Information theory and sequences of land use: An application; The Professional Geographer 30 $174-179$.
Rouse J W Jr, Haas R H, Shell J A and Deering D W 1974 Monitoring vegetation systems in the Great Plains with ERTS; In: Third Earth Resources Technology Satellite1 Symposium, 10-14 December 1973, Vol. 1, Washington D.C., pp. 309-317.

Smits P C, Dellepiane S G and Schowengerdt R A 1999 Quality assessment of image classification algorithms for land-cover mapping: A review and a proposal for a costbased approach; Int. J. Remote Sens. 20 1461-1486.

Sobrino J A, Jimenez-Munoz J C and Paolini L 2004 Land surface temperature retrieval from LANDSAT TM 5; Remote Sens. Environ. 90 434-440.

Song C, Woodcock C E, Seto K C, Pax-Lenney M and Macomber S A 2001 Classification and change detection using Landsat TM data; Remote Sens. Environ. 77 $241-246$.

Story M and Congalton R 1986 Accuracy assessment: A user's perspective; Photogramm. Eng. Remote Sens. 52 397-399.

Tang J, Wang L and Yao Z 2007 Spatio-temporal urban landscape change analysis using the Markov chain model and a modified genetic algorithm; Int. J. Remote Sens. 28(15) 3255-3271, doi: 10.1080/01431160600962749.

Voogt J A and Oke T R 2003 Thermal remote sensing of urban climates; Remote Sens. Environ. 86 370-384.

Weng Q 2002 Land use change analysis in the Zhujiang delta of China using satellite remote sensing, GIS and stochastic modelling; J. Environ. Manag. 64 273-284.

Wu Q, Li H, Wang R, Paulussen J, Hec Y, Wang M, Wang B and Wang Z 2006 Monitoring and predicting land use change in Beijing using remote sensing and GIS; Landscape and Urban Planning 78 322-333.

Zhang X, Yan G, Li Q, Li Z-L, Wan H and Guo Z 2006 Evaluating the fraction of vegetation cover based on NDVI spatial scale correction model; Int. J. Remote Sens. 27 5359-5372.

Zhang Q, Wang J, Peng X, Gong P and Shi P 2002 Urban built-up land change detection with road density and spectral information from multi-temporal Landsat TM data; Int. J. Remote Sens. 23(15) 3057-3078.

Zhang X, Kang T, Wang H and Sun Y 2010 Analysis on spatial structure of landuse change based on remote sensing and geographical information system; Int. J. Appl. Earth Observation Geoinform. 12S S145-S150.

Zhou Q and Hou Q 2009 The broad landuse pattern and landuse change in the last two decades; In: Hong Kong, Macau and the Pearl River Delta: A Geographical Survey (ed.) Wong K K, Hong Kong Educational Publishing Co., Hong Kong, pp. 68-98.

Zhao Y 2003 Principles and Methods for Remote Sensing: Applications and Analysis; Science Press, Beijing. 